https://doi.org/10.31874/2309-1606-2018-22-1-224-239

УДК: 167.7: 37.11

\title{
Лариса КИЯЩЕНКО
}

\section{MАТЕТИКА - \\ ТРАНСДИСЦИПЛИНАРНАЯ \\ ПАРАДИГМА ОБРАЗОВАНИЯ (СЛУЧАЙ БИОЭТИКИ)}

\section{Аннотация}

Целью статьи является использование ре-

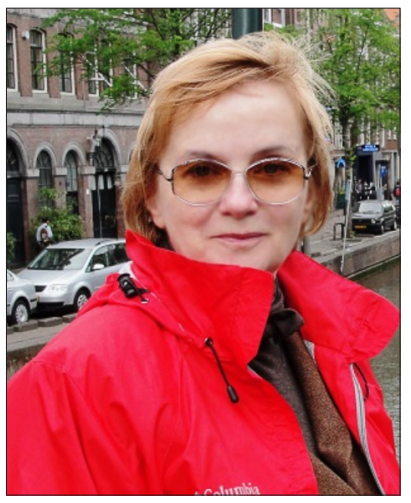
сурсов философии трансдисииллинарности для обоснования актуальности и эвристической значимости понятия «матетика», введённого чешским педагогом-гуманистом Я.А. Коменским три столетия назад для различения и установления координаций в едином образовательном процессе педагогических практик обучения и само-обучения студентов. Современная интерпретация идей матетики на примере проблем биоэтического образования осуществляется с привлечением концепции философии науки Т. Куна и Р. Мертона в контексте постнеклассических исследований. Введено представление о «синдроме парадигмальности», которое возникает как результат философской рефлексии над особенностями становления постнеклассической матрицы развития современного научного знания. Одним из определяюших его факторов является концептуализация и институализация процессов обеспечения преемственности знаний (образования) и постоянных инновационных преобразований, происходящих в обществе. Наиболее адекватной формой философско-методологической рефлексии в этой ситуации, по мысли автора, является философия трансдисциплинарности как интегрирующий механизм не только дисииплинарного знания, но и образования и инноватики - необходимых составляющих социальной системы, направленной на самообновление. Философия трансдисциплинарности и философия образования имеют во многом аналогичное парадигмальное строение, ориентированное иелевой причиной действующего лица на самообучение - матетику. Целевая причина задает проектный характер парадигмальных построений в образовании и биоэтике. В первую очередь, это уточнение проблемного поля, обучение и научение действовать в нем согласно существующим правилам и креативному характеру проектной деятельности, а также ориентация на ценностные приоритеты сообщества, выраженные как в символических обобщениях, так и неявных формах (М. Поляни) личностного знания и практики.

Ключевые слова: матетика, синдром парадигмальности, биоэтика, 4ПМ, этос науки, парадигма, междисциплинарность, трансдисциплинарность, философия науки. 


\section{Основания матетики}

Современный образовательный тренд состоит из попыток выявить новые тенденции в многообразии размерностей образовательной действительности, плюрализме педагогической деятельности, множественности представлений об образе человеческого в человеке. Нельзя не заметить, что он формируется на фоне усиливающейся стандартизации образовательного процесса, пронумерованных программ, выработки единого образца компетентности. Существует мнение, что за каждой образовательной системой, как правило, стоит философия образования, двигающаяся в развилке интервала между двумя позициями: «сознанияо-мире образования», «сознания-в-жизни образования». При этом в последнее время все больший вес приобретает имманентная позиция, включающая понимание в процесс и акты образования (Огурцов, Платонов, 2004: 6). Это обстоятельство делает легитимным инновационную форму философии образования, которая разворачивается не в расходящейся развилке, о которой говорилось выше, а в интервале выделенной диспозиции, между «сознанием-о-мире образования» и «сознанием-вжизни образования» - философию трансдисциплинарности, которая строится на основании умения задавать вопросы, не ожидая окончательных ответов. Этот интервал, «территория» особой ответственности, которая совмещает мировоззренческие, философские компоненты критического мышления «-о-» и реальные практики «-в-» обучении и учении. Особую роль на этой территории исполняет критическая рефлексия - принадлежность философского мышления, инициирующая себя во взаимодействии внешней, «остраненной» (Шкловский) позиции и «участной» (Бахтин), интимной позиции, которая выводит на авансцену следующую пару действующих лиц - учителя и ученика. Их отношения попадают под свод не простых правил обучения и учения, которые в своем взаимодействии относятся как к учителю, так и к ученику. Существует мнение, что человек, повторяющий деятельность, заданную в образце сто раз, вполне может ничему не научиться. Тот, кто повторяет, не учится. Однако это распространенное мнение вызывает сомнение, поскольку повторить образец практически невозможно. Ведь он образец. Его можно только у-своить, сделать в некотором приближении своим. Освоение происходит только тогда, когда в дело включается установочная рефлексия, за счет которой и выделяются сами схемы деятельности - способы решения практических задач, опирающиеся на предданные аргументацию и последующие рассуждения существующей у действующего лица установки, которая ни в коем случае не является чисто субъективным состоянием; наоборот, она представляет собой 
специфическое целостное отражение, именно некий процесс объективных обстоятельств ситуации, так сказать, голотоксический процесс, в котором субъект впервые приходит в соприкосновение с объектом и воспринимает его в его сущности, она выражает целостную готовность субъекта к определенной активности (Узнадзе, 2001: 405, 407). Образовательная деятельность, рассматриваемая обобщенно, например, с точки зрения концепции непрерывного образования, провозглашенная ЮНЕСКО в 1972 году или же преобразующего обучения (Mezirow, 1997: 74, 5-12) представляет собой «челночное» движение чередующихся деятельностей - предметной и рефлексивной, совмещенных в одном лице - его участника (преподавателя и учащегося). Задача непрерывного образования заключается в переходе как учащихся, так и преподавателей в рефлексирующее состояние, которое предполагает способность поддержания контактов и коммуникаций, а также приоритетность развития познавательной и эмоциональной компетентности (Giddens, 1998: 125), обеспеченной культурной осведомленностью не только локальными обстоятельствами «здесь и теперь». В связи с таким образом понимаемой философией образования можно и нужно говорить о транскультурной компетентности индивида, которая выстраивается как образовательная стратегия и практическое задание. Речь идет о деятельности, в основе которой лежит критическое и гетерологическое мышление, способность к культурной трансгрессии и номадическому трансверсальному движению, коммуникативная этика и эмоциональная развитость, открытость к Другому как проявления новой универсальности культуры мира (Горбунова, 2014: 141-167). Последняя дается не только как существующее фоновое (контекстуальное) знание и понимание, но и как задание самому действующему лицу, научающемуся на своем опыте жить сообща в этом мире.

\section{Источники матетики}

Уже триста лет назад Я. М. Коменский в своей педагогической теории и практике задает образец (парадигму) присутствия в ней совместных, но различенных подходов: дидактики и матетики. Дидактика была наукой об обучении (преподавании). Обучать - делать так, чтобы и другой знал то, что некто знает. Матетика говорила об умении <науке, искусстве, технике> учиться, об учении, что предполагало: 1) знание, что вещь есть, 2) знание содержания, смысла вещи, 3) знание назначения, применения вещи (Коменский, URL). Эрих Янч полсотни лет назад задумывался о возможности аксиоматического подхода общего характера в деле координации дисциплинарных и междисциплинарных исследо- 
ваний образовательных систем. Кроме того, он рассматривал «науку, образование и инновации как высокие примеры целесообразной человеческой деятельности», которая имеет «решающее значение для развития общества и окружающей среды», а соответствующие траектории социального развития являются «мощными факторами координации между образованием и инновационными процессами, которые могут быть названы трансдисциплинарными» (Jantsch, 1972: 97-121). Сегодня в качестве бурно развивающихся областей современных трансдисциплинарных исследований рассматриваются теория сложности (синергетика), исследования будущего (futures studies) и когнитивная наука. Высказываются предположения, что именно трансдисциплинарные исследования, по-видимому, определят облик науки в среднесрочном будущем (Князева, 2011), что не может ни сказываться на образовательном процессе (Буданов, URL), (Мокий М., Мокий В., 2014). Трансдисциплинарные практики преподавания распространяются по всему миру, меняя программы преподавания в вузах, выходя за их стены при выборе способов поведения в экстремальной ситуации повседневного опыта. Можно сказать, что идеи матетики не исчезли за прошедшие столетия, трансформировавшись за последние годы, продолжают свое существование в новых формах, решая актуальные проблемы философии образования. Матетика как наука об учении (самостоятельно направляемом обучении) противопоставляется классической дидактике как науке о преподавании. В ней развиваются идеи Т. Гилберта, В. Колберга, Э. Морена, Б. Николеску, С. Пейперта, анализируется и уточняется ряд понятий и принципов, которые являются ключевыми для трансдисциплинарного понимания природы как общей матетики, так и матетики частной, конкретизированной для обучения в цифровых сетях (Фрайссин, 2016). Все это является ответом на возникновение новых требований к системе образования, связанных с переходом от индустриального к информационному обществу, ведет к диверсификации и усложнению институций образования, разноречию в трактовке целей и идеалов образования, которое фиксируется как многопарадигмальность педагогического знания (Огурцов, Полетаев, 2004: 12).

Множественная парадигмальность образовательного процесса не в последнюю очередь связана со сложной структурой самой парадигмы (идеи Куна) и особой роли в ее осуществлении действующих лиц (идеи Мертона). Последние, действуя согласно образцам, заложенным в структуре парадигмы, осуществляют по сути своей проектную деятельность, лежащую по большому счету в основе образовательного процесса. Поскольку проектная деятельность предоставляет возможность существования и осуществления себя в системе деятельности, 
способствует активизации в преодолении сопротивления неизвестного, неопределенного, неоднозначного, ориентации на решение проблемы. Проект - это нелинейный процесс и непредсказуемый результат, рекурсивно влияющий на начало деятельности, перепроверяя ее предпосылки. Интервальная критичность пронизывает проектную деятельность между тем, что было - есть - будет, с учетом своего инакомыслия и другого. Концептуализированная проектность, считает Генисаретский, основана на синергии, остранении и со-действии личного и надличного, природного, начал культуры. Проектная культура - рефлексия творческой активности (Генисаретский, 1987) - вплетена в философию образования, ориентированная на трансдисциплинарное взаимодействие (Гребенщикова, Киященко, 2013: 210-223). Во-первых, и прежде всего, потому что она инновационна в том смысле, что необходимость в философствовании возникает в кризисной ситуации, в ситуации смыслового сдвига, поиска новых оснований. Это относится не только к отдельно взятой личности, но и к социуму, к конкретным научным дисциплинам, к художественному творчеству (Тульчинский, 2009: 105). Ключевой особенностью проектной деятельности является социогуманитарное сопровождение решений реальных проблем жизненного мира (экологии, здоровья, образования, нормотворчества в познании и практике, общественной безопасности и др.) с учетом нередуцируемой сложности взаимоотношений социогуманитарного и естественнонаучного знаний, что обусловливает поиск и выбор ориентированного на конвергенцию социально-культурного, нормативно-ценностного, методологического инструментария. Все выше сказанное, в конечном счете, и привело к активизации роли и значения личности, сознания как источника, средства и результата общественного и исторического развития, созданию целостной системы деятельности, содержащей в себе как необходимый аккомпанемент образовательный импульс как для заказчика, так и исполнителя следовать трансдисциплинарной парадигме образования - матетике. Матетика, имея своим истоком трансдисциплинарную парадигму, содержит философскую составляющую, о которой уже говорилось выше. Подчеркнем определяющий ее характер - характер практической философии (Киященко, Тищенко, 2004a: 11-20; 2004b: 179-198), когда инновационная мысль разворачивается с помощью нарождающихся дефиниций при обращении к актуальному опыту, вобравшему в себя нетленный запас традиций. Принципы, которые лежат в основе трансдисциплинарной парадигмы, порождают и поддерживают определенного рода стилистику философской рефлексии поведения, взаимообучения и учения. Одним из таких убедительных примеров является биомедицинская практика и биоэтика. 


\section{Праксеология матетики}

Начиная с 90-х годов биомедицинская практика и обсуждение проблем биоэтики переживают по-настоящему революционный бум (Hood Affrays, 2013:URL). При этом редкая публикация обходится без такого понятия как парадигма, и нельзя не заметить, что употребление этого понятия случается как само собой разумеющееся, на подобии клише, «стертой метафоры». Однако представляется актуальным рассмотреть сам термин парадигма в недалекой исторической ретроспективе, обращаясь к творчеству Т. Куна и Р. Мертона, чьи идеи, по нашему мнению, формируют то неявное знание, которое может объяснить столь частое его употребление сегодня, в том числе в современных дискурсах, например, о персонализированной медицине как частном случае биоэтики. «Тенденции развития современной модели практического здравоохранения плотно концентрируются вокруг достижений активно разрабатываемого направления, получившего название предиктивно-превентивной и персонализированной медицины (ПППМ). Ожидается, что его развитие способно стабилизировать показатели заболеваемости, существенно снижая масштабы хронизации заболеваний и, соответственно, инвалидности, сокращая традиционно высокие расходы на лечение уже заболевших людей» (Бодрова, Костюшев, 2013: 58). Новейшие достижения геномики, протеомики и других направлений молекулярной биологии обеспечили своеобразную реинкарнацию философской проблемы личности, но уже в поле общих и конкретных медицинских проблем. Персонализация выступила маркером новой парадигмы для медицины и здравоохранения (Gefenas, Cekanauskaite, 2011: 141-147).

Этот поворот в развитии медицинской практики и научных исследований может быть оценен с точки зрения гуманитарных традиций философии и психологии. С этой точки зрения, ПППМ представляет собой попытку перейти от научных исследований и терапевтической практики, в значительной степени ориентированных на среднестатистического пациента, к исследованиям и практике, которые были бы чувствительны к уникальным биологическим и личностным особенностям конкретного пациента. При этом, наличествует тенденция сводить понятие персонализации к учету уникальных генетических, как и иных биологических маркеров в диагностике, предсказании и лечении заболеваний. Поэтому, для выражения специфики личностного подхода некоторые авторы предлагают включить четвертое П к ПППМ - участную (participatory) медицину. Личностный аспект в данном случае реализуется наиболее адекватно в праве и способности пациентов (клиентов) со-участвовать и научаться в принятии наиболее существенных медицинских решений, которые их касаются. 
В теоретической биоэтике это понимание представлено в принципе автономии. Принципиальным моментом является то обстоятельство, что персонализированная медицина с необходимостью оказывается и превентивной. Если обычное терапевтическое действие, в определенном смысле, направлено на предшествующие (локализованные в прошедшем времени события) причины, вызвавшие то или иное страдание, то персонализация означает необходимость освоения будущего, превентивной деятельности здесь и сейчас. Реальное действие приобретает дополнительное измерение: актуальное просматривается через перспективу потенциального, приобретает модус «может быть» проекта. Пациент научается стать автором своей биографии, или соавтором фрагмента биографии, связанного с ситуацией страдания. Причем, если в обычной врачебной деятельности соавторство пациента достаточно ограничено, то в отношении превентивной деятельности именно пациент научается быть едва ли не основным действующим лицом, ответственным автором своей жизни (образа жизни).

По сути, основываясь на достижениях молекулярной биологии, позволяющей выявить неблагоприятные и благоприятные задатки и способы улучшения (enhancement) возможных сценариев развития жизненных событий, перед человеком (пациентом) возникает уникальная возможность освоить своеобразный «форсайт-проект» своей жизни в наиболее перспективном направлении. Причем спектр благоприятного исхода может не замыкаться только на описании состояния страдания пациента. Обстоятельства течения болезни могут оказаться не безразличными в той или иной степени не только для него, но и для других вовлеченных в этот случай участников. Дело в том, что персонализированная медицина, образует новую образовательную конфигурацию социализации ее исполнителей по данному конкретному случаю. «На определенном этапе жизни общества эта необходимость выступает в виде ценностно закрепленных форм социальной потребности. Потребность индивида быть личностью становится условием формирования у других людей способности видеть в нем личность, жизненно необходимую для поддержания единства, общности, преемственности, передачи способов и результатов деятельности и, что особенно важно, установления доверия друг к другу, без чего трудно надеяться на успех общего дела» (Петровский, 2008: 358-359).

Условием возможности построения биографического форсайта является: трансдисциплинарный полилог естественно-научных, гуманитарных и профанных дискурсов. Если естественно-научный дискурс, следуя закрепленной традицией за наукой предоставлять среднестатистические, обобщенные доказательные свидетельства об изучаемом 
явлении (пример доказательной медицины), то гуманитарный дискурс ориентирован на индивидуальные, конкретные события и случаи через спектроскоп ценностей и смыслов нарративного описания (феноменологическая и герменевтическая интерпретации). Дискурс «простаков» (больного, его родственников, людей за него ответственных), не отягощенных профессиональным медицинским знанием, содержит в себе неисчерпаемый ресурс экзистенциального переживания, которое сообразовывает человека на протяжении его жизни и выдвигает на решения философских вопросов - жизни и смерти, добра и зла - проверку на качество и меру человеческого в человеке (Тищенко, 2015: 96-118).

\section{Выводы как пролегомены к действию}

Мера человеческого в человеке в сфере биомедицины, т.е. то, что составляет его основу как поступающей личности, - это умелое сочетание потребительского отношения к услугам врачевания с необходимостью учиться осознанно и информировано участвовать в поиске оптимального решения проблем конкретного состояния человека. Потребление услуг как самоцельное обращение к возможностям медикализированного общества в количественном измерении проходит проверку на возможность не только поддержания, но и качественного улучшения самоорганизующейся природы человеческого существа. Осознание себя как личности дается в какое-то мгновение, которое требует постоянного подтверждения в «пульсирующей» нити бытия в событиях выстраивания своей биографии, социально признанного феномена. Здесь очень важен практический (деятельный) ракурс, дающий реально увидеть меру человеческого в человеке. Она из идеализированной «есть» в диагнозе профессиональной медицинской практики смещается в виртуальное «может быть» в персональной «заботе о себе» (прогнозе), в личностной перспективе (Майленова, 2015: 70-84).

Возникает проблема совмещения дифференцированной размерности, заложенной изначально в двояком толковании улучшения (enhancement). С одной стороны, уточнение шкалы оценивания преобразующей деятельности и его последствий персонально для данной личности, а с другой - уточнение конструирующей деятельности с точки зрения адаптивных возможностей социо-природного существования человека, его научению жить, работать и выстраивать свою неповторимую индивидуальность. Стоит задача выявления, научения и подтверждения в трансдисциплинарном полилоге комплексных и перспективных «единиц измерения» здоровья и стабилизации в течение жизни состояния человека, по которым мы будем отслеживать успех или не успех 
данной образовательной деятельности, определяя гуманитарную и морально-этическую составляющую научно-практической деятельности того или иного коллектива, сообщества, ориентированного на решение такого рода проблем.

В связи с этим возникает необходимость переосмысления проблем этоса современной науки. Проблема этоса научного познания, с нашей точки зрения, сегодня представлена, например, через переосмысление в современной культуре традиционных соотношений Истины и Блага, всеобщего и общезначимого, фундаментального и прикладного в научном познании, наконец, персональной и коллективной ответственности в проведении того или иного исследовании. Этос постнеклассической науки может быть рассмотрен через призму соотношения состояния или статуса научного знания в целом и его организующих «частей» - внутренних и внешних порядков, границ. Соотношение внутреннего и внешнего порядков, образующих системный феномен этоса науки, может быть проиллюстрировано различением внутренней и внешней стороны границы. «Граница системы есть не что иное, как вид и конкретность тех операций системы, которые ее индивидуализируют. Граница - это форма системы, другая сторона которой становится, тем самым, окружающим миром» (Луман, 2004: 78), образует основания ее жизнедеятельности. То, о чем идет речь, может быть соотнесено с нормами и ценностями, образующими научный этос, по Р. Мертону. Нормы в таком случае выражаются в форме позволений, запретов, предписаний, предпочтений и т. п. - факторов внутреннего обустройства научного знания. Ценности же соотносятся с целями и желаемыми результатами деятельности в данном научном сообществе, имеющими внешние формы проявления жизнедеятельности научного сообщества (Merton, 1970).

На ситуацию можно взглянуть и с позиции Куна (Кун, 1977: 230235), через «призму» парадигмы (дисциплинарной матрицы), которая содержит в себе мощный потенциал для реализации философской рефлексии над трансформациями современного научного познания. Особенность такого направления научной мысли состоит в том, что в ней одновременно происходит формирование как своего предмета, так и его методологического обеспечения в режиме реального времени научного сообщества, как правило, сформированного и объединенного конкретной практической задачей, запрос на решение которой пришел извне, из актуальных проблем жизненного мира. Нормы приобретают динамический характер, зависимость от целей, поставленных трансдисциплинарным сообществом. В предлагаемых обстоятельствах они работают контекстуально обусловлено: то как интегрирующее, то как дезинтегрирующее начало в образовании трансдисциплинарного сооб- 
щества. Право «собственности» в современном высоко коммерциализированном сообществе трансформирует норму ответственности каждого участника трансдисциплинарного общения. Ответственность в рамках корпорации (коллективная отчетность перед обществом), основанная на его собственности (материально-финансовом обеспечении научного исследования), порой вступает в конфликт с нормой ответственности ученого за сделанное персонально им (Мирская, 2008: 108-143).

«Но ведь опасность, - предупреждает В. Франкл, - заключается отнюдь не в специализации как таковой, да и не в недостатке универсализации, а скорее в той кажущейся тотальности, которую приписывают своим познаниям столь многие ученые в заявляемых ими претензиях на “тотальное знание” (Ясперс). Тогда, когда это происходит, наука превращается в идеологию» (Франкл, 1990: 46). Как нам представляется, полемическая заостренность решения трансдисциплинарных проблем, их приуроченность к конкретным обстоятельствам делает указанную угрозу чрезмерной. И, тем не менее, не забудем отмеченное в свое время Хабермасом, что «сказанное относится, прежде всего, к наукам, которые используют реконструктивную методику и опираются на дотеоретическое знание субъектов, компетентных в своих суждениях, действиях и речах, а также на системы знаний, передаваемые культурной традицией, для того, чтобы прояснить предполагаемые в качестве всеобщих рациональные основания опыта и суждения, действия и языкового взаимопонимания. Трансцендентальные и диалектические способы обоснования, в их умеренном варианте, вполне могут в этом помочь; ведь они сохраняют еще свою действенность только в отношении реконструктивных гипотез, пригодных для дальнейшей разработки в эмпирических взаимосвязях. Примеры такой вовлеченности философии в сотрудничество наук я наблюдаю всюду, где философы вместе со всеми участвуют в разработке теории рациональности, не выдвигая фундаменталистских или всеобъемлющих абсолютистских притязаний. Скорее, они работают в нетвердой надежде, что только благодаря удачному сочетанию различных теоретических фрагментов удастся достичь того, что философия некогда рассчитывала добиться в одиночку» (Хабермас, 2000: 28). Ведь претензия философа на осмысление метафизических оснований эпохи и их публичное признание «есть мужество ставить под вопрос прежде всего истину собственных предпосылок и пространство собственных целей» (Хайдеггер, 1993: 40).

Эта ответственная (в ответе на вопрос, заданный экзистенциальной ситуацией) транспозиция свидетеля как участника делает его философом современного (постнеклассического) типа. Особенность стилистики философствования в данном месте и времени состоит в осознании 
ответственности не только в отношении выбора себя, но и в отношении сохранения открытости (коммуникабельности) другому обретает конкретный и практический характер. Причем обе формы ответственности совместно реализуются в процессе становления обновленной парадигмальной установки образования, что находит свое выражение в широко обсуждаемой проблеме персонализированный медицины, которая выходит на актуальные проблемы, поставленные матетикой - трансдисциплинарной парадигмой образования.

\section{Ссылки}

Бодрова Т.А., Костюшев Д.С., Антонова Е.Н., Гнатенко Д.А., Бочарова М.О., Лопухин Ю.М., Пальцев М.А., Сучков С.В. (2013). Введение в предиктивно-превентивную медицину: опыт прошлого и реалии дня завтрашнего. Вестник Российской академии медицинских наук, 68(1), 58-64. DOI:10.15690/vramn.v68i1.539. URL: https://cyberleninka.ru/.../vvedenie-v-prediktivno-preventivnuyu-meditsinuopyt-pros...

Буданов В.Г. Трансдисциплинарное образование в XXI веке: проблемы становления [Электронный ресурс] URL: http://spkurdyumov.ru/education/transdisciplinarnoeobrazovanie-v-xxi-veke/

Генисаретский О. И. (2006). Проектная культура и концептуализм. В: Сборник научных трудов ВНИИТЭ, 52, Центр гуманитарных технологий [Электронный pecypc] URL: http://gtmarket.ru/laboratory/expertize/2006/2682

Горбунова Л. (2014). Транскультурна компетентність: освітній шлях до глобальної культури миру. Філософія освіти. Philosophy of Education, 2 (15), 141-167. URL: www.philosopheducation.com

Гребенщикова Е., Киященко Л. (2013). Трансдисциплинарные основания инноваций в образовании. Філософія освіти. Philosophy of Education, 1(12), 210-223. URL: www.philosopheducation.com

Киященко, Л. П., Тищенко, П. Д. (2004а). Философия трансдисциплинарности как опыт практического философствования. Практична философія, Киев, 2, 11-20.

Киященко, Л. П., Тищенко, П. Д. (2004b). Философия трансдисциплинарности как опыт практического философствования. Практична философія, Киев, 3, 179-198.

Князева Е.Н. (2011). Трансдисциплинарные стратегии исследования. Вестник Томского государственного педагогического университета, 10 (112), 193-201. URL: https://cyberleninka.ru/article/n/transdistsiplinarnye-strategii-issledovaniy

Коменский, Ян Амос. Матетика, т. е. наука учения [Электронный ресурc] URL:www. bim-bad.ru/biblioteka/article_full.php?aid=2123\&binn_rubrik_pl...155

Кун Т. (1977). Структура научных революций. С вводной статьей и дополнениями 1969 г. М.: Прогресc. URL: www.biometrica.tomsk.ru/Kuhn.pdf

Луман Н. (2004). Общество как социальная система. Пер. с нем. А. Антоновский. М: Издательство “Логос". URL: www.yanko.lib.ru/books/cultur/luman-ob_kak_socsistema-81.pdf

Майленова Ф.Г.(2015). Этико-психологические аспекты персонализированной медицины. В: Рабочие тетради по биоэтике. Вып.21: Философско-антропологические основания персонализированной медицины (междисииплинарный ана- 
лиз): сб. науч. ст. М.: МОСГУ, 70-84. URL: https:// www.bioethics.ru/_Images/ Catalog/488-1-33.pdf

Мирская Е.3. (2008). Этос науки: идеальные регулятивы и повседневные реалии. В: Этос науки /отв. ред. Л. П. Киященко, Е. З. Мирская. М.: Академия. URL: http:// www. courier-edu.ru/cour0812/1161.htm

Мокий М.С., Мокий В.С. (2014). Трансдисциплинарность в высшем образовании: экспертные оценки, проблемы и практические решения. Современные проблемы науки и образования, 5 [Электронный ресурс] URL: http://www.science-education. $\mathrm{ru} / \mathrm{ru} /$ article/view?id=14526

Огурцов А. П., Платонов В. В. (2004). Образы образования. Западная философия образования. XX век. СПб.: РХГИ. URL: http://www. sibfrontier.ru/wp.../OgurtsovA.-Platonov-V.-Obrazyi-obrazovaniya_2004_chast-1.pd

Петровский В. А. (2002). Потребность быть личностью. В: Психология личности в трудах отечественных психологов. СПб, 225-227. URL: https://www.twirpx.com > ... >

Тищенко П.Д. (2015). Философские основания персонализированной медицины (ПМ): казусы А. Джолии, М. Шнайдер. В: Рабочие тетради по биоэтике. Bыn.21: Философско-антропологические основания персонализированной медицины (междисциплинарный анализ): сб. науч. ст. М.: МОСГУ, 96-118. URL: www. bioethics.ru/_Images/Catalog/488-1-33.pdf

Тульчинский Г.М. (2009). Философия как технология перманентной инновации образования. Философские науки, 9, 102-116. URL: www.emory.edu/INTELNET/ Fil_nauki_2009_9.pdf

Узнадзе Д. Н. (2001). Психология установки. СПб.: Питер, «Психология-классика». URL: https://www.bookap.info/book/uznadze_psihologiya_ustanovki/

Фрайссин Ж. (2016). Матетика: трансдисциплинарная концепция обучения в цифровых сетях. Непрерывное образование: ХXI век. Выпуск 1 (13). URL: http:// 1l121.petrsu.ru/journal/total_list.php?year $=2016$

Франкл В. (1990). Философия человеческой ответственности. В: Человек в поисках смысла. Сборник: Пер. с англ. и нем. /Общ. ред. Л. Я. Гозмана и Д. А. Леонтьева; вст. cm. Д. А. Леонтьева. М.: Прогресс. URL: https://bib.social/psihologiya.../chelovekpoiskah-smyisla-moskva-progress.html

Хабермас Ю. (2000). Моральное сознание и коммуникативное действие. СПб.: Наука. URL: https://library.sakharov-center.ru/.../moralnoe-soznanie-i-kommunikativnoedejstvie.html?...

Gefenas, E., Cekanauskaite, A., Tuzaite, E., Dranseika, V, Characiejus, D. (2011). Does the "new philosophy" in predictive, preventive and personalised medicine require new ethics? EPMA J. Jun; 2(2). URL: https://mafiadoc.com/does-the-anew-philosophyain-predicti...

Hood, L., Affrays, C. (2013). Participatory medicine: a driving force for revolutionizing healthcare. Genome Medicine, 5:110. URL: http://genomemedicine.com/content $/ 5 / 12 / 110$

Jantsch, E. (1972). Towards interdisciplinarity and transdisciplinarity in education and innovation. In: L. Apostel, G. Berger, A. Briggs \& G. Michaud (Eds.), Interdisciplinarity: Problems of teaching and research in universities, 97-121. Nice: University of Nice. URL: http://journals.sagepub.com/doi/abs/10.1177/0263276415592245

Merton, R.K. (1970). Science. Technology and Society in Seventeenth Century England. N.Y., URL: https://doi.org/10.1086/368484 
Mezirow, J. (1997). Transformative Learning: Theory to Practice. New Directions for Adult and Continuing Education, 74, 5-12. URL: http://dx.doi.org/10.1002/ace

\section{References}

Bodrova, T.A., Kostushev, D.S., Antonova, E.N., Gnatenko, D.A., Bocharova, M.O., Lopukhin, Y.M., Pal'tsev, M.A., Suchkov, S.V. (2013). Introduction into PPPM: experience of the past and tomorrow's reality. Annals of the Russian academy of medical sciences, 68(1), 58-64 [In Russian]. DOI:10.15690/vramn.v68i1.539. URL:https:// cyberleninka.ru/.../vvedenie-v-prediktivno-preventivnuyu-meditsinu-opyt-pros...

Budanov, V.G. Transdisciplinary education in the 21 st century: problems of formation. The site of S.P. Kurdyumov [In Russian]. URL: http://spkurdyumov.ru/education/transdisciplinarnoe-obrazovanie-v-xxi-veke/

Comenius, Jan Amos. Mathetics, that is the science of learning. URL:www.bim-bad.ru/ biblioteka/article_full.php?aid=2123\&binn_rubrik_pl...155

Freissin J. (2016). Mathetics: Transdisciplinary Learning Concept in Digital Networks. Continuous Education: The 21st Century, Issue 1 (13) [In Russian]. URL: http:// 11121. petrsu.ru/journal/total_list.php?year=2016

Frankl, V. (1990). Philosophy of Human Responsibility. In: Man in Search of Meaning. Collection: Trans. from English. M: Progress. URL: https://bib.social/psihologiya.../ chelovek poiskah- smyisla-moskva-progress.html

Genisaretsky, O.I. (2006). Project culture and conceptualism. In: Collection of scientific papers VNIITE, 52. Electronic publication: Center for Humanitarian Technologies [In Russian]

Gorbunova, L. (2014). Transcultural Competence: Way of Education to Global Culture of the Peace [In Ukrainian]. Filosofiya osvity. Philosophy of Education, 2 (15), 141-167. URL: www.philosopheducation.com

Grebenshchikova, Y., Kiyashchenko, L. Transdisciplinary Foundation of Innovation in Education [In Russian]. Filosofiya osvity. Philosophy of Education, 1 (12), 210-223. URL: www.philosopheducation.com

Gefenas, E., Cekanauskaite, A., Tuzaite E., Dranseika, V., Characiejus, D. (2011). Does the "new philosophy" in predictive, preventive and personalised medicine require new ethics? EPMA J. Jun; 2(2). URL: https://mafiadoc.com/does-the-anew-philosophyain-predicti...

Habermas, J. (2000). Moral consciousness and communicative action. St. Petersburg, Nauka. URL: https://library.sakharov-center.ru/.../moralnoe-soznanie-i-kommunikativnoe-dejstvie.html?...

Hood, L., Affrays, C. (2013). Participatory medicine: a driving force for revolutionizing healthcare. Genome Medicine, 5:110. URL: http://genomemedicine.com/content $/ 5 / 12 / 110$

Jantsch, E. (1972). Towards interdisciplinarity and transdisciplinarity in education and innovation. In: L. Apostel, G. Berger, A. Briggs \& G. Michaud (Eds.), Interdisciplinarity: Problems of teaching and research in universities, 97-121. Nice: University of Nice. URL: http://journals.sagepub.com/doi/abs/10.1177/0263276415592245

Kiyashchenko, L.P., Tishchenko, P.D. (2004a). The philosophy of transdisciplinarity as an experience of practical philosophizing. Praktychna filosofiya (Practical philosophy), Kiev, 2, 11-20. 
Kiyashchenko, L.P., Tishchenko, P.D. (2004b). The philosophy of transdisciplinarity as an experience of practical philosophizing. Praktychna filosofiya (Practical philosophy), Kiev, 3, 179-198.

Knyazeva, E.N. (2011). Transdisciplinary research strategies [In Russian]. Bulletin of the Tomsk State Pedagogical University, 10(112), 193-201. URL: https://journals.tsu.ru/engine/download.php?id=79064\&area=files

Kuhn, T. (1977). The structure of scientific revolutions. With introductory article and additions of 1969 [In Russian]. M: Progress. URL: www.biometrica.tomsk.ru/Kuhn.pdf

Luman, N. (2004). Society as a social system [In Russian]. Trans. from German by A. Antonovsky. M.: Publishing house "Logos". URL: www.yanko.lib.ru/books/cultur/lumanob_kak_soc-sistema-81.pdf

Mailenova, F.G. (2015). Ethical and psychological aspects of personalized medicine [In Russian]. Workbooks on bioethics. Issue 21: Philosophical-Anthropological Foundations of Personalized Medicine (Interdisciplinary Analysis). M.: MOSGU, 70-84. URL: www. yanko.lib.ru/books/cultur/luman-ob_kak_soc-sistema-8l.pdf

Merton, R.K. (1970). Science, Technology and Society in Seventeenth Century England. N.Y., URL: https://doi.org/10.1086/368484

Mezirow, J. (1997). Transformative Learning: Theory to Practice. New Directions for Adult and Continuing Education, 74, 5-12. URL: http://dx.doi.org/10.1002/ace

Mirskaya, E.Z. (2008). Ethos of science: ideal regulatives and everyday realities [In Russian]. In: Ethos of science. Ed. L.P. Kiyashchenko, E.Z. Mirskaya. M.: Academia. URL: www. courier-edu.ru/cour0812/1161.htm

Mokiy, M.S., Mokiy, V.S. (2014). Transdisciplinarity in Higher Education: Expert Assessments, Problems and Practical Solutions [In Russian]. Modern Problems of Science and Education, 5. [Electronic resource]. URL: http://www.science-education.ru/ru/article/ view? $\mathrm{id}=14526$

Ogurtsov, A.P., Platonov, V.V. (2004). Images of education. Western philosophy of education. XX century. [In Russian]. St. Petersburg: RHGI. URL: www. sibfrontier.ru/wp.../ Ogurtsov-A.-Platonov-V.-Obrazyi-obrazovaniya_2004_chast-1.pd

Petrovsky, V.A. (2002). The need to be a person [In Russian]. In: Psychology of personality in the works of domestic psychologists. St. Petersburg, 225-227. URL: https://www.twirpx. com

Tishchenko, P.D. (2015). Philosophical grounds for personalized medicine (PM): the incidents A. Jolie M. M. Schneider [In Russian]. Workbooks on bioethics. Issue 21: Philosophical-Anthropological Foundations of Personalized Medicine (Interdisciplinary Analysis). M.: MOSGU. 96-118. URL: www.bioethics.ru/_Images/Catalog/488-1-33.pdf

Tulchinsky, G.M. (2009). Philosophy as a technology of permanent education innovation [In Russian]. Philosophical sciences, 09, 102-116. URL: www.emory.edu/INTELNET/ Fil_nauki_2009_9.pdf

Uznadze, D.N. (2001). Psychology of the installation. St. Petersburg: Peter. "Psychologyclassics" [In Russian]. URL: https://www.bookap.info/book/uznadze_psihologiya_ ustanovki/

\section{Лариса Кіященко. Матетика - трансдисциплінарна парадигма освіти (ви- падок біоетики)}

Метою статті є використання ресурсів філософії трансдисциплінарності для обгрунтування актуальності і евристичної значимості поняття «матети- 
ка», уведеного чеським педагогом-гуманістом Я.А. Коменським три століття тому для розрізнення і встановлення координацій в єдиному освітньому процесі педагогічних практик навчання і само-навчання студентів. Сучасна інтерпретація ідей матетики на прикладі проблем біоетичної освіти здійснюється із залученням концепції філософії науки Т. Куна і Р. Мертона в контексті постнекласичних досліджень. Уведено уявлення про «синдром парадигмальності», яке виникає як результат філософської рефлексії над особливостями становлення постнекласичної матриці розвитку сучасного наукового знання. Одним із визначальних його чинників є концептуалізація і інституалізація процесів забезпечення наступності знань (освіти) і постійних інноваційних перетворень, що відбуваються в суспільстві. Найбільш адекватною формою філософсько-методологічної рефлексії в цій ситуації, на думку автора, є філософія трансдисциплінарності як інтегруючий механізм не тільки дисциплінарного знання, а й освіти та інноватики - необхідних складових соціальної системи, спрямованої на самовідновлення. Філософія трансдисциплінарності і філософія освіти мають багато в чому аналогічну парадигмальну будову, орієнтовану цільовою причиною дієвої особи на самонавчання - матетику. Цільова причина задає проектний характер парадигмальних побудов в освіті і біоетиці. В першу чергу, це уточнення проблемного поля, навчання і научіння діяти в ньому згідно з існуючими правилами і креативним характером проектної діяльності, а також орієнтація на ціннісні пріоритети спільноти, виражені як в символічних узагальненнях, так і неявних формах (М. Поляні) особистісного знання і практики.

Ключові слова: матетика, синдром парадигмальності, біоетика, 4ПМ, етос науки, парадигма, міждисциплінарність, трансдисциплінарність, філософія науки.

\section{Larisa Kiyashchenko. Mathetiks - a transdisciplinary education paradigm (the case of bioethics)}

The novelty of the article is related to the use of the resources of the philosophy of transdisciplinarity to justify the relevance and heuristic importance of the concept of "Mathetiks", introduced by the Czech pedagogue-humanist Jan Amos Comenius (Komensky) to refer to practices of self-education.

The aim of the article is to use resources of the philosophy of transdisciplinarity to justify the relevance and heuristic importance of the concept of "Mathetiks", introduced by the Czech pedagogue-humanist J. A. Komensky three centuries ago to distinguish and establish coordination in the unified educational process of pedagogical practices of teaching and self-learning of students. The modern interpretation of the ideas of mathetiks (on the example of the problems of bioethical education) is carried out with the implementation of the concepts of the philosophy of science Th. Kuhn and R. Merton in the context of post-nonclassical studies. The notion of „paradigmatic syndrome“, which arises as a result of philosophical 
reflection on the peculiarities of the formation of the post-classical matrix of the development of modern scientific knowledge, is introduced. One of its defining factors is the conceptualization and institutionalization of processes to ensure continuity of knowledge (education) and constant innovative changes taking place in society. The most adequate form of philosophical and methodological reflection in this situation, according to the author, is the philosophy of transdisciplinarity as an integrating mechanism not only of the disciplinary knowledge, but also of education and innovation, the necessary components of the social system aimed at self-renewal. The philosophy of transdisciplinarity and the philosophy of education have in many ways similar paradigm structures, oriented target cause of the actor on self - education -mathetiks. The target specifies the reason for the project-based nature of the paradigmatic constructs in education and bioethics. First of all, this is the clarification of the problem field, training and teaching to act in it according to the existing rules and the creative nature of project activities. Orientation to the value priorities of the community expressed both in symbolic generalizations and implicit forms (M. Polanyi) of personal knowledge and practice.

Keywords: matetiks, paradigmatic syndrome, bioethics, 4PM, ethos of science, paradigm, interdisciplinarity, transdistsiplinarity, science philosophy.

Киященко Лариса Павловна, доктор философских наук, ведущий научный сотрудник сектора междисципинарных проблем научно-технического развития ИФРАН.

E-mail: larisakiyashchenko@gmail.com; ORCID:https://orcid.org/00000002-4244-5732

Kiyashchenko Larisa Pavlovna, doctor of philosophical science, Leading Researcher of the Sector of Interdisciplinary Problems of Scientific and Technical Development Institute of Philosophy Russian Academy of Sciences.

E-mail: larisakiyashchenko@gmail.com; ORCID:https://orcid.org/00000002-4244-5732 